(с) 3.А. Калмыкова*, И.В. Кононенко, И.А. Скляник, М.В. Шестакова, Н.Г. Мокрышева

Национальный медицинский исследовательский центр эндокринологии, Москва

Актуальнейшим вопросом как отечественного, так и мирового здравоохранения является пандемия новой коронавирусной инфекции COVID-19, вызванной вирусом SARS-CoV-2. Уже установлено, что наибольшая подверженность заболеванию и более тяжелое его течение отмечаются у лиц с различными хроническими заболеваниями, в частности с сахарным диабетом (СД). Однако стали появляться первые данные о развитии на фоне новой коронавирусной инфекции стрессовой, или транзиторной, гипергликемии. В данной статье приведен обзор сообщений зарубежных врачей-исследователей о зарегистрированных случаях гипергликемии на фоне COVID-19. Описаны возможные механизмы развития гипергликемии при COVID-19 с учетом особенностей патогенеза и течения заболевания, репродукции SARS-CoV-2 по данным отечественной и зарубежной литературы.

КЛЮЧЕВЫЕ СЛОВА: COVID-19; SARS-CoV-2; стрессовая гипергликемия; $\beta$-клетка; «цитокиновый шторм»

\title{
HYPERGLYCEMIA AND POSSIBLE MECHANISMS OF $\beta$-CELL DAMAGE IN PATIENTS WITH COVID-19
}

(c) Zilya A. Kalmykova*, Irina V. Kononenko, Igor A. Sklyanik, Marina V. Shestakova, Natalia G. Mokrysheva

Endocrinology Research Centre, Moscow, Russia

Progressive decrease in the weight and functional reserve of $\beta$-cells is one of the main pathogenetic mechanisms of development of type 2 diabetes mellitus (DM2). The rate of progression of these processes is strictly individual, which largely determines the course of DM2 and the effectiveness of the therapy. As a rule, apoptosis and necrosis are the main mechanisms of $\beta$-cell damage and death in CD2. At the same time, recent studies allow us to consider the destruction and death of $\beta$-cells as the outcome of other types of programmed cell death (PCG), the role of innate immunity in the Genesis of CD2 IS actively discussed. This article provides an overview of the data of domestic and foreign literature of recent years regarding the molecular, intracellular characteristics of different types of $\beta$-cell PCG in CD2. The results of studies aimed at studying the possible factors and processes leading to their launch are presented.

KEYWORDS: COVID-19; SARS-CoV-2; stress hyperglycemia; $\beta$-cell; "cytokine storm"

Всего за несколько месяцев заболевание, вызванное новым коронавирусом SARS-CoV-2 и получившее название COVID-19, достигло масштабов пандемии. По данным Всемирной организации здравоохранения (ВОЗ), на 26.06.2020 г. в мире насчитывается более 9,5 млн заболевших с лабораторно подтвержденным диагнозом, более 450 тыс. из которых умерли от последствий вирусной пневмонии. В Российской Федерации на 26.06.2020 г. зарегистрировано 620 тыс. заболевших [1]. Особенности патогенеза заболевания и влияния его на организм широко обсуждаются в отечественной и зарубежной литературе. Результаты наблюдений китайских, американских и итальянских врачей-исследователей свидетельствуют о более тяжелом течении заболевания у лиц с хроническими заболеваниями, в частности с сахарным диабетом (СД). Однако появляются данные и о потенциальном воздействии нового коронавируса SARS-CoV-2 на углеводный обмен: описаны случаи стрессовой гипергликемии (CГ) на фоне COVID-19 [2].

СГ - синдром повышения уровня глюкозы в крови, развивающийся при различных стрессовых состояниях у лиц без предшествующих нарушений углеводного обмена. Стрессовые состояния включают обширные оперативные вмешательства, острые заболевания, массивные травмы, а также некоторые инфекционные заболевания. Изучение СГ вызывает большой интерес, с одной стороны, в связи с ее ассоциацией с более высокой летальностью и количеством осложнений у пациентов, находящихся в тяжелом состоянии. С другой - в связи с тем, что нередко выявление манифестной гипергликемии приводит к ошибочной верификации диагноза СД и назначению в дальнейшем терапии, которая может привести к гипогликемиям и другим нежелательным явлениям. В то же время стрессовые состояния могут привести к дисбалансу углеводного обмена и развитию не только транзиторной СГ, но и, в дальнейшем, СД [3].

\section{СТРЕССОВАЯ ГИПЕРГЛИКЕМИЯ ПРИ COVID-19}

Возбудители коронавирусной инфекции известны достаточно давно. Для всех представителей вирусов SARS характерно внедрение в клетки-мишени через 
рецептор - ангиотензинпревращающий фермент типа 2 (АПФ2) [4]. Одной из первых опубликованных работ, посвященных оценке взаимосвязи коронавируса SARS и углеводного обмена, является исследование, проведенное в Китае в 2009 г. В проспективное наблюдение были включены 39 пациентов без СД и терапии стероидными препаратами в анамнезе, госпитализированных по поводу лабораторно подтвержденной коронавирусной пневмонии. У 20 из этих 39 пациентов (51\%) отмечалась гипергликемия, сохраняющаяся на протяжении нескольких дней. Уровень гликемии нормализовался к окончанию госпитализации у всех пациентов. Повторная оценка состояния углеводного обмена у этих пациентов была проведена через 3 года. СД был установлен лишь у 2 из 39 человек (5\%), что подтверждает транзиторный характер гликемии, развившейся на фоне коронавирусной инфекции, т.е. СГ. Проводилось иммуногистохимическое исследование биоптатов легких, сердца, почек и поджелудочной железы 42-летнего пациента, умершего от коронавирусной пневмонии, при этом экспрессия АПФ2 отмечалась во всех исследуемых органах, в том числе и в поджелудочной железе. Причем уровень экспрессии АПФ-2 в клетках эндокринной части был выше, чем в экзокринной $[5,6]$. Учитывая единый механизм внедрения вирусов SARS, можно предположить возможность возникновения гипергликемии и при COVID-19.

Ранние отчеты из Уханя (Китай) в период настоящей пандемии свидетельствуют о развитии СГ у $51 \%$ пациентов с новой коронавирусной инфекцией. По последним опубликованным данным, в США из 1122 пациентов без СД и терапии стероидными препаратами в анамнезе, госпитализированных по поводу COVID-19, у 257 пациентов (22,9\%) была отмечена СГ. Развитие СГ было подтверждено повышением уровня глюкозы в капиллярной крови выше 9,9 ммоль/л (180 мг/дл) в течение нескольких дней $[7,8]$. Результаты другого наблюдения 85 пациентов, проведенного в США, также демонстрируют развитие СГ у госпитализированных пациентов [9].

Таким образом, впервые зафиксированная гипергликемия у пациентов с COVID-19 встречается достаточно часто. В настоящее время в связи с коротким промежутком времени с начала пандемии и отсутствием проспективных наблюдений пациентов с СГ вопрос развития СД, вызванного SARS-CoV-2, остается открытым. Опубликован лишь один клинический случай дебюта СД и развития кетоацидоза на фоне COVID-19 у пациента 37 лет без установленных ранее каких-либо нарушений углеводного обмена и приема стероидных средств в анамнезе. Однако уровень $\mathrm{HbA}_{1 c}$ 14,2\% свидетельствует о том, что SARSCoV-2 в данном случае, вероятно, выступил триггером манифестации заболевания, а не причиной его развития [10]. Необходимо отметить, что последние отчеты ученых-исследователей из Китая демонстрируют не только развитие гипергликемии на фоне заболевания, но и повышенный уровень $\mathrm{HbA}_{1 c}(>6,0 \%)$ у многих пациентов без СД в анамнезе. Показатели $\mathrm{HbA}_{1 с}$ коррелировали с маркерами воспаления, гиперкоагуляции и уровнем сатурации кислородом крови $\left(\mathrm{SaO}_{2}\right)$ у пациентов с COVID-19 [11]. Однако следует учитывать, что высокий уровень $\mathrm{HbA}_{1 с}$ при этом может быть связан не только с гипергликемией, но и с дефицитом железа, витамина $\mathrm{B}_{12^{\prime}}$ приемом некоторых лекарственных средств [12]. Возможно изменение уровня $\mathrm{HbA}_{1 с}$ и в связи с развитием метгемоглобинемии, установленной у пациентов с COVID-19 [12, 13].

\section{ПАТОГЕНЕЗ РАЗВИТИЯ ГИПЕРГЛИКЕМИИ ПРИ COVID-19}

Цитотоксические эффекты большинства возбудителей вирусных инфекций в отношении панкреатических $\beta$-клеток достаточно изучены [14]. Установлено, что вирусная инфекция является одним из этиологических факторов развития СД 1 типа (СД1). Многие вирусные возбудители обладают прямым повреждающим действием на цитоплазматическую мембрану (ЦПМ) $\beta$-клеток, что приводит к персистенции в них вируса. Развивается аутоиммунная реакция, сопровождающаяся лимфоидной инфильтрацией, деструкцией островков Лангерганса и развитием СД1 [14, 15]. Данный механизм подтвержден многими экспериментальными и клиническими исследованиями. У лиц с впервые выявленным СД1 определяются титры антител к вирусспецифичному IgM [16, 17]. Работы на животных моделях демонстрируют дебют СД после инфицирования мышей различными вирусами, что сопровождается репродукцией вирусов в клетках поджелудочной железы и их деструкцией $[14,18]$. Следует отметить, что манифестация СД1 на фоне вирусных инфекций чаще происходит у лиц с генетической предрасположенностью. Одним из наиболее крупных исследований, посвященных изучению взаимосвязи вирусных инфекций и СД1, является TEDDY. За 15 лет наблюдения было зарегистрировано 87327 случаев респираторных вирусных инфекций у детей и подростков, которые имели HLA-генотип, acсоциированный с высоким риском СД1. В 5,8\% случаев развился СД1, причем риск манифестации СД1 возрастал ежегодно на 5,6\% [19].

Несмотря на то что SARS-CoV-2 малоизучен, можно предположить следующие патогенетические механизмы развития СГ и СД. Жизненный цикл SARS-CoV начинается с проникновения в клетку путем эндоцитоза: S-белок связывается с его рецептором АПФ2, угнетая его дальнейшую экспрессию, затем расщепляется, вследствие чего мембраны вируса и эндосомы сливаются и и происходит высвобождение РНК. В результате трансляции образуются полипротеины рр1а и 1ab, участвующие в формировании копии РНК вируса, а также восемь молекул мРНК, ассоциированных с синтезом вирусных белков в просвете между эндоплазматическим ретикулумом (ЭР) и комплексом Гольджи. Вирионы собираются в цитоплазме и выходят из клетки путем экзоцитоза (рис. 1) [20].

Высокая экспрессия АПФ2 отмечается не только в слизистых верхних дыхательных путей, альвеолярных клетках типа 2 [21, 22], но и в кардиомиоцитах, проксимальных почечных канальцах, печени, эпителии толстой кишки и в поджелудочной железе [23]. Такая локализация экспрессии АПФ2 может определять и развитие различных внелегочных проявлений заболевания, в частности СГ. Влияние SARS-CoV-2 на панкреатические $\beta$-клетки в настоящее время изучено недостаточно. Помимо прямого цитотоксического воздействия на клетку вследствие репликации вируса, возможно и опосредованное повреждение 


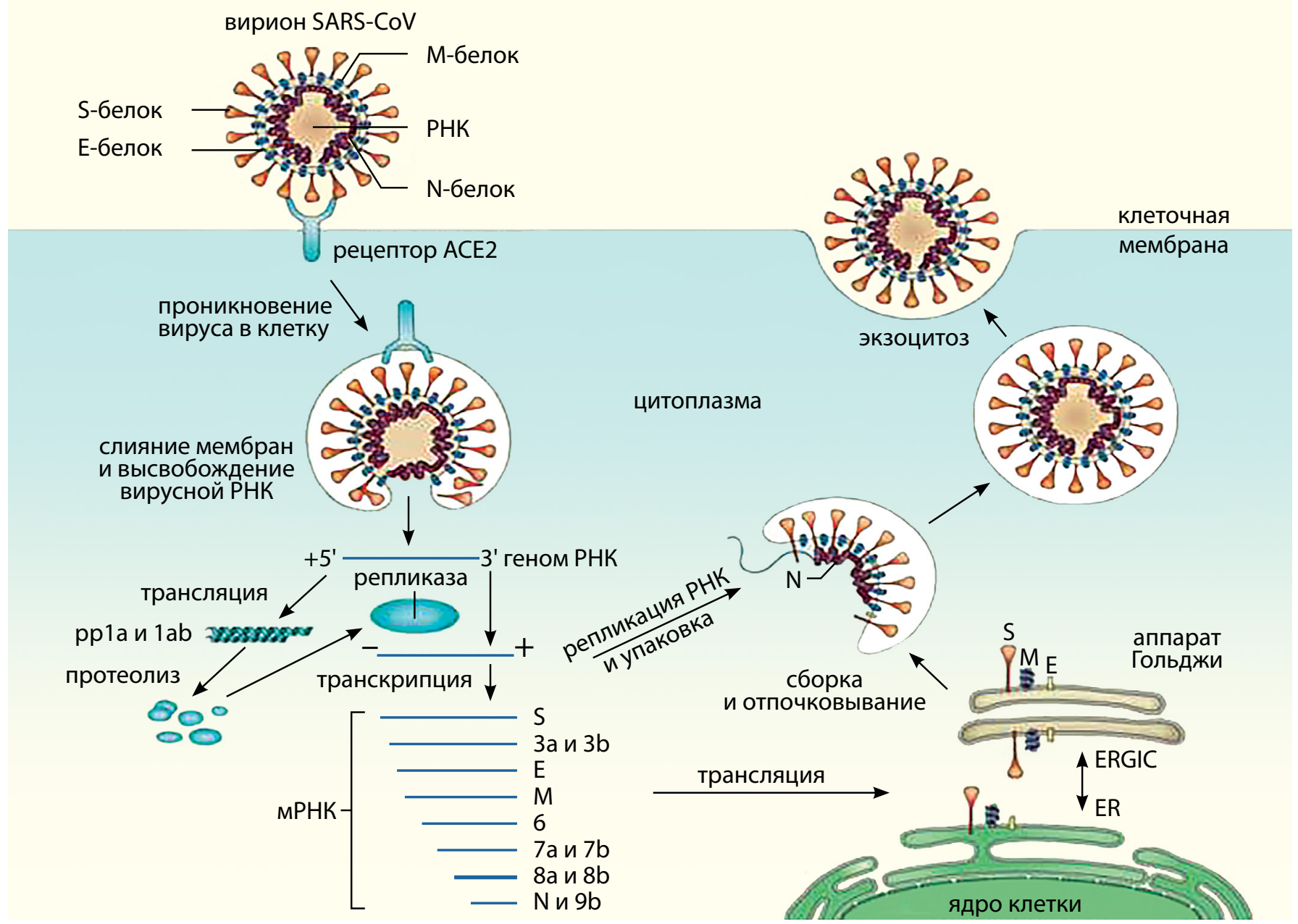

Рис. 1. Жизненный цикл SARS-CoV [20].

панкреатических $\beta$-клеток, связанное со снижением экспрессии АПФ2 на поверхности $\beta$-клеток после проникновения в них SARS-CoV-2. Протективное действие АПФ2 на функциональное состояние $\beta$-клеток связано с увеличением активности ангиотензина 1-7 и снижением активности ангиотензина 2, который приводит к апоптозу $\beta$-клеток, снижению их дифференцировки, выработке свободных радикалов и локальному воспалению. Таким образом, снижение экспрессии АПФ2 на поверхности $\beta$-клеток после проникновения в них SARS-CoV-2 может привести к снижению функциональной активности $\beta$-клеток и недостаточности инсулина (рис. 2) [24, 25].

Другим механизмом развития гипергликемии при COVID-19, не связанным с АПФ2, является активация врожденной иммунной системы. Репродукция вируса в организме запускает неспецифический иммунный ответ, заключающийся в нескольких последовательных этапах: выход вируса за пределы ворот инфекции, виремия, активация моноцитарно-макрофагальной системы; запуск синтеза цитокинов и развитие «цитокинового шторма»; поражение эндотелия сосудов, нарушение микроциркуляции - появление начальных признаков системного поражения органов и тканевой гипоксии. «Цитокиновый шторм» - реакция организма на вирусную инфекцию, выражающаяся в гиперпродукции провоспалительных цитокинов - TNFa, интерферонов I и II типов, IL-1及, IL-6, IL-8 [26]. Актива- ция синтеза цитокинов приводит к деструктивным последствиям, которые проявляются массовым апоптозом клеток эндотелия сосудов и являются фоном для развития системной воспалительной реакции $[26,27]$. Участие иммунной системы в патогенезе СД изучается давно. Установлено, что СД1 развивается в результате Т-клеточно-опосредованной деструкции $\beta$-клеток поджелудочной железы. Особенности взаимосвязи СД 2 типа (СД2) с иммунной системой также активно обсуждаются. Результаты исследований последних лет позволяют рассматривать СД2 как заболевание, ассоциированное с генерализованным воспалением и активацией врожденной иммунной системы. Об этом свидетельствуют частое повышение уровней C-реактивного белка, сывороточного амилоида $A$, TNF-a, IL-1 $\beta$ и IL-6 у пациентов с ожирением и СД2 и их снижение при снижении веса и нормализации уровня гликемии [28]. Длительное время апоптоз рассматривали в качестве основного процесса, приводящего к снижению массы $\beta$-клеток. Вместе с тем экспериментальные работы демонстрируют развитие дисфункции $\beta$-клеток в результате других типов программируемой клеточной гибели, в частности пироптоза. Пироптоз - тип клеточной гибели, связанный с активацией врожденной иммунной системы. При воздействии определенных факторов на рецепторы врожденного иммунитета в клетках моноцитарного ряда, тропных к определенным клеткам или тканям, происходит 
Ангиотензиноген

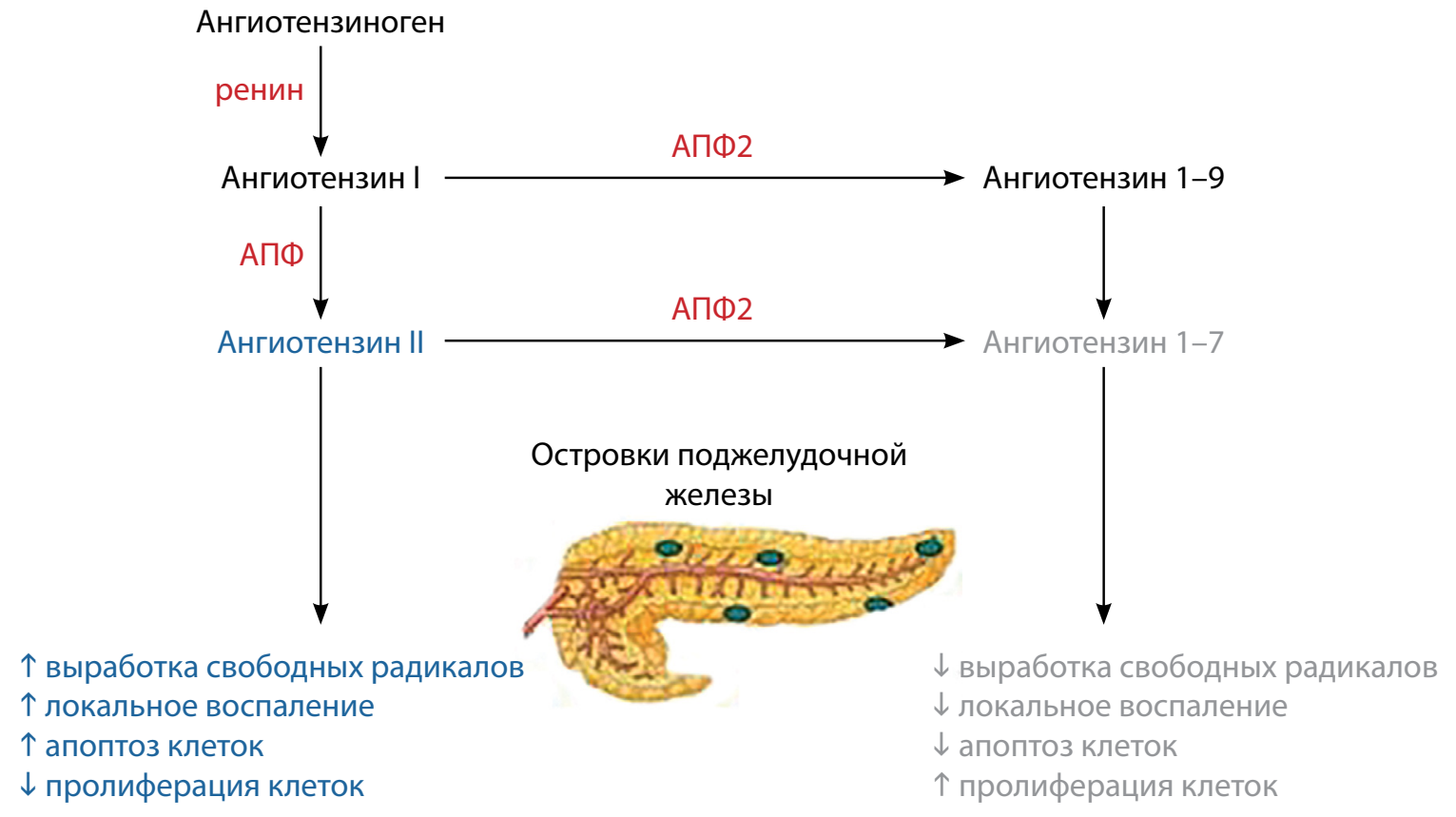

Рис. 2. Механизм протективного воздействия ангиотензинпревращающего фермента типа 2 на панкреатические $\beta$-клетки [25].

активация мультибелкового цитоплазматического комплекса - инфламмасом - с последующей выработкой IL-1 $\beta$ и IL-18 и повреждением клеток в результате локального иммунного ответа $[29,30]$. Активация инфламмасом при COVID-19 возможна как вследствие прямого влияния SARS-CoV-2 на рецепторы врожденного иммунитета, так и опосредованного - в результате воздействия свободных радикалов, которые также могут инициировать пироптоз. «Цитокиновый шторм», часто развивающейся при COVID-19, сопровождается гиперреактивностью врожденного иммунитета, а значит, и ускоренным запуском всех ассоциированных с ним процессов, в частности, и пироптоза. Однако, учитывая, что «цитокиновый шторм» сопровождается высоким уровнем IL-1 $\beta$, а пироптоз - выработкой инфламмасомами IL-1 $\beta$, остается открытым вопрос, является ли пироптоз следствием «цитокинового шторма» или это два параллельных идущих процесса.

Безусловно, в условиях COVID-19, каки другихстрессовых для организма состояний, причиной развития СГ может стать выработка контринсулярных гормонов, ассоциированных со стрессовой ситуацией в организме, - глюкокортикоидов и катехоламинов. Развитие СГ в этом случае связано с влиянием гормонов стресса на различные звенья метаболизма. Вследствие активации липолиза повышается уровень свободных жирных кислот, что, с одной стороны, ведет к угнетению аэробного окисления глюкозы с последующей стимуляцией глюконеогенеза, с другой - оксидативному стрессу. Контринсулярные гормоны также подавляют секрецию инсулина, стимулируют глюконеогенез и гликогенолиз в печени, вызывая гипергликемию. Повышение уровня катехоламинов ассоциировано со снижением выработки серотонина и его метаболитов, что ведет к уменьшению выделения эндотелиального оксида азота, повышению образования свободных радикалов, уменьшению активности антиоксидантной защиты и активации оксидативного стресса [31]. В случае недостаточности адаптивных процессов антиоксидантной системы организма в условиях генерализованного воспаления, часто сопровождающего COVID-2019, возможно развитие и генерализованного оксидативного стресса. В таком случае гипергликемия может носить не только транзиторный характер. Действие свободных радикалов может привести к программируемой клеточной гибели $\beta$-клеток - к апоптозу, пироптозу $[30,32]$.

Таким образом, влияние SARS-CoV-2 на углеводный обмен определяется несколькими возможными факторами: это и прямое цитотоксическое воздействие на $\beta$-клетку вследствие репликации вируса, и опосредованное повреждение панкреатических $\beta$-клеток, связанное со снижением экспрессии АПФ2 на их поверхности, развитием генерализованного воспаления с активацией системы врожденного иммунитета.

В случае развития СД после данной вирусной инфекции остается открытым вопрос о типе диабета. Как и после других вирусных инфекций, нельзя исключить риск развития аутоиммунного СД1, однако возможно развитие и дисфункции $\beta$-клеток у лиц, имеющих инсулинорезистентность. В этом случае вероятность развития СД2 выше у лиц, имеющих факторы риска: избыточную массу тела или ожирение, артериальную гипертензию и гиперлипидемию, отягощенный наследственный анамнез, гестационный СД и синдром поликистозных яичников в анамнезе и др. Повышение секреции стрессовых контринсулярных гормонов также приводит к усилению инсулинорезистентности. Учитывая последнюю классификацию СД, предложенную ВО3 в 2019 г., в случае развития СД после новой коронавирусной инфекции в дебюте заболевания может быть временно поставлен диагноз «неклассифицируемый СД» [33]. Дальнейшее наблюдение и обследование данных пациентов позволит определить тип СД. 


\section{ВЫВОДЫ}

Учитывая особенности репродукции SARS-CoV-2, можно предположить развитие гипергликемии как одного из внелегочных проявлений COVID-19. Ключевым механизмом при этом, вероятно, является повреждение панкреатических $\beta$-клеток. Особенности SARS-CoV-2 позволяют предположить, что деструктивное влияние вирусов на $\beta$-клетки может привести не только к транзиторной гипергликемии, но и развитию СД. Все это указывает на актуальность дальнейших исследований и наблюдения больных, перенесших COVID-19.

\section{ДОПОЛНИТЕЛЬНАЯ ИНФОРМАЦИЯ}

Конфликт интересов. Авторы декларируют отсутствие явных и потенциальных конфликтов интересов, связанных с публикацией статьи.

Участие авторов. Калмыкова 3.А. - концепция и дизайн работы, сбор и анализ материала, написание текста рукописи; Кононенко И.В. - концепция и дизайн работы, анализ материала, редактирование текста рукописи; Скляник И.А. - концепция и дизайн работы, редактирование текста рукописи; Шестакова М.В. - концепция и дизайн работы, редактирование текста рукописи; Мокрышева Н.Г. - концепция и дизайн работы, редактирование текста рукописи. Все авторы внесли существенный вклад в подготовку статьи, прочли и одобрили финальную версию перед публикацией.

\section{СПИСОК ЛИТЕРАТУРЫ | REFERENCES}

1. World Health Organization. Coronavirus disease (COVID-2019) situation reports-67. Avalable from: https://www.who.int/docs/ default-source/coronaviruse/situation-reports/20200327-sitrep-67covid-19.pdf?sfvrsn=b65f68eb_4

2. Brufsky A. Hyperglycemia, hydroxychloroquine, and the COVID-19 pandemic. J Med Virol. 2020;92(7):770-775. doi: https://doi.org/10.1002/jmv.25887

3. Marik PE, Bellomo R. Stress hyperglycemia: an essential survival response! Crit Care. 2013;17(2):305. doi: https://doi.org/10.1186/cc12514

4. Hoffmann M, Kleine-Weber H, Schroeder S, et al. SARS-CoV-2 cell entry depends on ACE2 and TMPRSS2 and is blocked by a clinically proven protease inhibitor. Cell. 2020;181(2):271-280.e8. doi: https://doi.org/10.1016/j.cell.2020.02.052

5. Yang JK, Lin SS, Ji XJ, Guo LM. Binding of SARS coronavirus to its receptor damages islets and causes acute diabetes. Acta Diabetol. 2010;47(3):193-199. doi: https://doi.org/10.1007/s00592-009-0109-4

6. Yao XH, LiTY, He ZC, et al. [A pathological report of three COVID-19 cases by minimal invasive autopsies. (In Chinese)]. Zhonghua Bing Li Xue Za Zhi = Chinese J Pathol. 2020;49(5):411-417. doi: https://doi.org/10.3760/cma.j.cn112151-20200312-00193

7. Bode B, Garrett V, Messler J, et al. Glycemic characteristics and clinical outcomes of COVID-19 patients hospitalized in the United States. J Diabetes Sci Technol. 2020;14(4):813-821. doi: https://doi.org/10.1177/1932296820924469

8. Thaweerat W. Current evidence on pancreatic involvement in SARS-CoV-2 infection. Pancreatology. 2020;S1424-3903(20)30184-8. doi: https://doi.org/10.1016/j.pan.2020.05.015

9. lacobellis $G$, Penaherrera CA, Bermudez LE, et al. Admission hyperglycemia and radiological findings of SARS-CoV2 in patients with and without diabetes. Diabetes Res Clin Pract. 2020;164:108185. doi: https://doi.org/10.1016/j.diabres.2020.108185

10. Chee YJ, Ng SJ, Yeoh E. Diabetic ketoacidosis precipitated by Covid-19 in a patient with newly diagnosed diabetes mellitus. Diabetes Res Clin Pract. 2020;164:108166. doi: https://doi.org/10.1016/j.diabres.2020.108166

11. Wang Z, Du Z, Zhu F. Glycosylated hemoglobin is associated with systemic inflammation, hypercoagulability, and prognosis of COVID-19 patients. Diabetes Res Clin Pract. 2020;164:108214. doi: https://doi.org/10.1016/j.diabres.2020.108214

12. Gallagher EJ, Le Roith D, Bloomgarden Z. Review of hemoglobin A1C in the management of diabetes. J Diabetes. 2009;1 (1):9-17. doi: https://doi.org/10.1111/j.1753-0407.2009.00009.x

13. Naymagon $L$, Berwick $S$, Kessler $A$, et al. The emergence of methemoglobinemia amidst the COVID-19 pandemic. Am J Hematol. 2020:ajh.25868. doi: https://doi.org/10.1002/ajh.25868

14. Op de Beeck A, Eizirik DL. Viral infections in type 1 diabetes mellitus - why the $\beta$ cells? Nat Rev Endocrinol. 2016;12(5):263-273. doi: https://doi.org/10.1038/nrendo.2016.30

15. Jaeckel E, Manns M, Herrath M. Viruses and diabetes. Ann N Y Acad Sci. 2002;958(1):7-25. doi: https://doi.org/10.1111/j.1749-6632.2002.tb02943.x

16. Szopa TM, Titchener PA, Portwood ND, et al. Diabetes mellitus due to viruses - some recent developments. Diabetologia. 1993;36(8):687-695. doi: https://doi.org/10.1007/BF00401138
17. Devendra D, Liu E, Eisenbarth GS. Type 1 diabetes: recent developments. BMJ. 2004;328(7442):750-754. doi: https://doi.org/10.1136/bmj.328.7442.750

18. Yoon JW, Austin M, Onodera T, et al. Isolation of a virus from the pancreas of a child with diabetic ketoacidosis. N Engl J Med. 1979;300(21):1173-1179. doi: https://doi.org/10.1056/NEJM197905243002102

19. Lönnrot $M$, Lynch $K F$, Elding Larsson $H$, et al. Respiratory infections are temporally associated with initiation of type 1 diabetes autoimmunity: the TEDDY study. Diabetologia. 2017;60(10):1931-1940 doi: https://doi.org/10.1007/s00125-017-4365-5

20. Du L, He Y, Zhou Y, et al. The spike protein of SARS-CoV - a target for vaccine and therapeutic development. Nat Rev Microbiol. 2009;7(3):226-236. doi: https://doi.org/10.1038/nrmicro2090

21. Zou X, Chen K, Zou J, et al. Single-cell RNA-seq data analysis on the receptor ACE2 expression reveals the potential risk of different human organs vulnerable to 2019-nCoV infection. Front Med. 2020;14(2):185-192. doi: https://doi.org/10.1007/s1 1684-020-0754-0

22. $\mathrm{Xu} \mathrm{H}$, Zhong L, Deng J, et al. High expression of ACE2 receptor of 2019-nCoV on the epithelial cells of oral mucosa. Int J Oral Sci. 2020;12(1):8. doi: https://doi.org/10.1038/s41368-020-0074-x

23. Rabi FA, Al Zoubi MS, Kasasbeh GA, et al. SARS-CoV-2 and Coronavirus Disease 2019: what we know so far. Pathogens. 2020;9(3):231. doi: https://doi.org/10.3390/pathogens9030231

24. Simões e Silva A, Silveira K, Ferreira A, et al. ACE2, angiotensin-(1-7) and Mas receptor axis in inflammation and fibrosis. Br J Pharmacol. 2013;169(3):477-492. doi: https://doi.org/10.1111/bph.12159

25. Batlle D, Jose Soler M, Ye M. ACE2 and diabetes: ACE of ACEs? Diabetes. 2010;59(12):2994-2996. doi: https://doi.org/10.2337/db10-1205

26. Ye $Q$, Wang $B$, Mao J. The pathogenesis and treatment of the 'Cytokine Storm' in COVID-19. J Infect. 2020;80(6):607-613. doi: https://doi.org/10.1016/j.jinf.2020.03.037

27. Mehta P, McAuley DF, Brown M, et al. COVID-19: consider cytokine storm syndromes and immunosuppression. Lancet. 2020;395(10229):1033-1034. doi: https://doi.org/10.1016/S0140-6736(20)30628-0

28. Emanuela F, Grazia M, Marco DR, et al. Inflammation as a Link between Obesity and Metabolic Syndrome. J Nutr Metab. 2012;2012:476380. doi: https://doi.org/10.1155/2012/476380

29. Guo H, Callaway JB, Ting JP. Inflammasomes: mechanism of action, role in disease and therapeutics. Nat Med. 2015;21(7):677-668. doi: https://doi.org/10.1038/nm.3893

30. Абатуров А.Е., Волосовец А.П., Юлиш Е.И. Роль NOD-подобных рецепторов в рекогниции патоген-ассоциированных молекулярных структур инфекционных патогенных агентов и развитии воспаления. Протеины NLR семейства, участвующие в регуляции процесса воспаления и иммунного ответа // Здоровье ребенка. - 2013. - № 5. - C. 150-155. [Abaturov AYe, Volosovets AP, Yulish Yel. The role of NOD-like receptors in recognition of pathogen-associated molecular patterns of infectious pathogens and in development of inflammation. Part 4. NLR family proteins are involved in the regulation of process of inflammation and immune response. Zdorov'e rebenka. 2013;(5):150-155. (In Russ.)] 
31. Мельниченко Г.А., Глинкина И.В., Суровцева Д.М. Другие типы диабета: контринсулярные гормоны и генетическая предрасположенность, новые возможности диагностики и лечения // Вестник РАMН. - 2012. - Т. 67. — №1. - C. 50-53. [Melnichenko GA, Glinkina IV, Surovceva DM. «Other types» of diabetes: contra-insular hormones and genetic predisposition new horizons of diagnostics and treatment. Annals of the Russian academy of medical sciences. 2012;67(1):50-53. (In Russ.)]

32. Калмыкова 3.А., Кононенко И.В., Смирнова О.М., и др. Сигнальные пути гибели $\beta$-клеток при сахарном диабете
2 типа: роль врожденного иммунитета // Сахарный duaбem. - 2020. - T. 23. - № 2. - C. 174-184. [Kalmykova ZA, Kononenko IV, Smirnova OM, et al. Signaling pathways of $\beta$-cell death in type 2 diabetes: the role of innate immunity. Diabetes Mellitus. 2020;23(2):174-184. (In Russ.)]. doi: https://doi.org/10.14341/DM10242

33. World Health Organization. Classification of diabetes mellitus. WHO; 2019. Available from: https://apps.who.int/iris/ handle/10665/325182

\section{ИНФОРМАЦИЯ ОБ АВТОРАХ [AUTHORS INFO]}

*Калмыкова Зиля Асхатовна, аспирант [Zilya. A. Kalmykova, MD, PhD student]; адрес: Россия, 117036 Mосква, ул. Дм. Ульянова, д. 11 [address: 11 Dm. Ulyanova street, 117036 Moscow, Russian Federation]; ORCID: https://orcid.org/0000-0002-2612-5253; eLibrary SPIN: 1264-0320; e-mail: zilya.kalmykova@gmail.com

Кононенко Ирина Владимировна, к.м.н., в.н.с. [Irina V. Kononenko, MD, PhD, leading research associate]; ORCID: https://orcid.org/0000-0003-4929-1526; eLibrary SPIN 6528-7986; e-mail: shakhtarina@bk.ru

Скляник Игорь Александрович, н.c. [Igor A. Sklyanik, MD, research associate];

ORCID: https://orcid.org/0000-0002-7768-4717; eLibrary SPIN: 7081-8077; e-mail: sklyanik.igor@gmail.com

Шестакова Марина Владимировна, д.м.Н., профессор, академик PAH [Marina V. Shestakova, MD, PhD, Professor]; ORCID: https://orcid.org/0000-0002-5057-127X; eLibrary SPIN: 7584-7015; e-mail: nephro@endocrincentr.ru

Мокрышева Наталья Георгиевна, д.м.н., профессор, член-корр. PAH [Natalia G. Mokrysheva, MD, PhD, Professor]; ORCID: http://orcid.org/0000-0002-9717-9742; eLibrary SPIN: 5624-3875; e-mail: nm70@mail.ru

\section{ЦИТИРОВАТЬ:}

Калмыкова 3.А., Кононенко И.В., Скляник И.А., Шестакова М.В., Мокрышева Н.Г. Гипергликемия и возможные механизмы повреждения $\beta$-клеток у пациентов с COVID-19 // Сахарный диабет. - 2020. — T. 23. — №3. — C. $229-234$. doi: https://doi.org/10.14341/DM12485

\section{TO CITE THIS ARTICLE:}

Kalmykova ZA, Kononenko IV, Sklyanik IA, Shestakova MV, Mokrysheva NG. Hyperglycemia and possible mechanisms of $\beta$-cell damage in patients with COVID-19. Diabetes Mellitus. 2020;23(3):229-234. doi: https://doi.org/10.14341/DM12485 